\title{
Dos conceptos de la modernidad: religión y secularización
}

\author{
Two Modern Concepts: Religion and Secularization
}

\author{
Eduardo Zazo Jiménez \\ Universidad Autónoma de Madrid
}

DOI: http://dx.doi.org/10.15366/bp2018.19.007

Bajo Palabra. II Época. No19. Pgs: 149-170 


\section{Resumen}

Los debates contemporáneos sobre la religión y la secularización descansan en parte sobre la polisemia de estos términos. Este artículo ofrece una breve historia de los dos y defiende que: 1 . Ambos son conceptos modernos; 2. La secularización es un proceso complejo, diverso, no teleológico y plural; 3. "Religión" es un concepto tremendamente problemático, surgido en un marco específico (en la Europa de los siglos XV-XIX) y difícil de aplicar a otros ámbitos históricos y culturales. Por esta razón, el concepto de "religión" debería ser comprendido como una herramienta analítica para estudiar la vida social.

Palabras clave: religión, secularización, modernidad, laicidad, historia de las religiones, religiones mundiales.

\section{Abstract}

Contemporary debates on religion and secularization rest partially on the polysemy of these terms. This paper provides a short history of both and make the following claims: 1 . Religion and secularization are modern concepts; 2. Secularization is a complex, diverse, plural, non teleological process; 3. Religion is a highly problematic concept, arosen in a very specific stage (XV-XIX centuries in Europe), so it is difficult to apply to other cultures and periods of time. For that reason, "religion" should be understood as an analytical tool for studying social life.

Keywords: religion, secularization, modernity, secularity, history of religions, world religions. 


\section{Introducción}

LOS DEBATES CONTEMPORÁNEOS SOBRE LA RELIGIÓN y la secularización descansan en parte sobre la polisemia de estos términos. Existen múltiples interpretaciones sobre lo que es la religión; ampliaciones del término "religión" a movimientos como el comunismo o el neoliberalismo, productos como la Coca-Cola o fenómenos sociales como los deportes de masas; comprensiones antitéticas de la secularización, bien como supresión del elemento religioso, bien como su continuación subrepticia; adjetivaciones curiosas de la laicidad y del laicismo que soliviantarían a los legisladores de la ley francesa de 1905 o la española de 1933; analogías insólitas entre movimientos religiosos y movimientos políticos; una xenofobia y una islamofobia rampantes que se escudan en la libertad de expresión; disquisiciones metafísicas sobre la pertinencia del delito de blasfemia; y un largo etcétera. En esta situación de dispersión y diseminación conceptual, una breve exposición de carácter histórico-político y filosófico-histórico sobre el origen y el empleo de estos dos términos -religión y secularización- puede resultar útil para comprender mejor el alcance y los límites de las posiciones en liza. Este recorrido, sin embargo, no tiene una pretensión de exhaustividad, sino que se detendrá en aquellos aspectos centrales de carácter histórico y social que considero relevantes sobre esta cuestión.

\section{Las narrativas de la secularización}

Los debates Sobre La CONVIVENCIA EN EuRopa en relación con la religión suelen remitir a dos grandes tipos de narrativas, que por comodidad llamaré "teleológica" y "defensiva":

a) En primer lugar, encontraríamos la narrativa "teleológica" de la secularización ineluctable, según la cual el proceso histórico de secularización disminuiría progresivamente la influencia de la religión en la vida social y forzaría a todas las confesiones religiosas a asumir su sujeción, en cuestiones políticas, a autoridades no religiosas y a aceptar un marco de convivencia que las trascendería. El debate, por lo tanto, sería estipular los términos en que se realizaría esta "sujeción", y aquí entraría en juego la cuestión de la laicidad, esto es, la 
relación jurídica del Estado con las confesiones religiosas. Según este relato, dicho proceso de secularización se estaría cumpliendo -o incluso ya se habría cumplido- con el cristianismo (con alguna excepción puntual, sobre todo en países con pasado monoconfesional católico u ortodoxo, es decir, sin experiencia pasada de pluralidad religiosa y más intolerantes) y el gran tema de nuestro tiempo sería comprobar si el islam, presente en Europa como consecuencia de los movimientos migratorios desde el final de la Segunda Guerra Mundial, puede acomodarse a dicho proceso de secularización ${ }^{1}$.

Una variante más radical de esta narrativa estaría conformada por todos aquellos discursos que detectan nuevas religiones -nuevos falsos ídolos, en realidad- en fenómenos a primera vista no religiosos, como por ejemplo el capitalismo, el consumismo, la diversidad identitaria, etc. Su lucha se dirigiría contra todo tipo de religión, bien bajo la forma de las viejas iglesias, bien bajo la forma de nuevos obstáculos en apariencia no religiosos, pero supuestamente diseñados para impedir la consecución de una verdadera secularización. Sea como fuera, esta narrativa teleológica se inscribe en un relato de la "modernidad" que supondría una ruptura con un orden de cosas anterior calificado de religioso ${ }^{2}$. Por lo tanto, la modernidad resultante sería una modernidad secular, que alcanza dicho estadio mediante un proceso de secularización al que estarían llamadas todas las sociedades que quisieran alcanzar la modernidad, como si se tratara una calle de sentido único. La religión, para esta narrativa, es algo del pasado ${ }^{3}$, por suerte cada vez menos influyente, y la secularización un estado deseable.

\footnotetext{
${ }^{1}$ Véase una exposición crítica en Roy, O., La laïcité face à l'islam, Pluriel, Paris, 2013. Un rico y detallado panorama general de las posibles posiciones se encuentra en Romerales, E., "Reacciones en Europa frente al fanatismo islámico", en Romerales, E., Zazo, E. (eds.), Religiones en el espacio público, Gedisa, Barcelona,, 2016, pp. 77-104.

${ }^{2}$ Hay que destacar que un gran número de filósofos y teóricos sociales del siglo XIX y de principios del siglo XX destacaban el carácter pasado de la religión, no otorgándole futuro alguno o un futuro muy limitado: para Hegel, la religión es una forma de manifestación del espíritu absoluto destinada a ser superada por la filosofía; para Comte, la religión es una etapa histórica necesaria que sin embargo tiene que ser superada, de acuerdo con la ley de los tres estados (teológico, metafísico y científico o positivo); para Marx, la religión es el opio del pueblo, la expresión no material de la miseria material, y también la protesta contra la misma, pero la crítica de la religión tiene que transformarse en crítica del derecho; para Nietzsche, la religión es el debilitamiento de los instintos vitales; para Weber, la religión jugó un papel crucial en la formación del capitalismo que domina nuestras vidas, pero ya no; para Durkheim, la religión es un fenómeno social del que cada vez cobramos mayor conciencia en tanto que propiamente social, etc. También los sociólogos de la religión europeos del siglo XX han tendido a pensar la tesis de la secularización en su versión más fuerte, considerando la religión como un vestigio; los sociólogos estadounidenses de la religión no lo hicieron así y por eso se ha propuesto la imagen de una Europa secular frente a unos Estados Unidos religiosos. Véase Berger, P., Davie, G., y Fokas, E., Religious America, Secular Europe? A Theme and Variations, Ashgate, Aldershot, 2008.

${ }^{3}$ Aunque con muchos matices, las grandes corrientes de la izquierda desde el siglo XIX (republicanismo radical, socialismo, comunismo o anarquismo) pueden inscribirse en esta narrativa para la cual la religión es un asunto del pasado que tiene que marcharse por el sumidero de la historia.
} 
b) En segundo lugar, encontraríamos la narrativa "defensiva” que critica la razón secular como nueva falsa religión que pretende destruir y/o suplantar a las religiones tradicionales. Los motivos de la desconfianza ante esta razón ajena a lo religioso pueden ser variados: por su fatídica falta de sensibilidad hacia lo religioso; por estar cargada de una supuesta religiosidad que no quiere reconocer en sí misma ${ }^{4}$; por proceder de doctrinas religiosas cuyo origen desconoce o no quiere conocer ${ }^{5}$; por replicar ilegítimamente algunos rasgos o características religiosas; etc. Aunque las diferentes propuestas sean muy heterogéneas entre sí, suelen tener en común la denuncia de la insostenibilidad a largo plazo de una sociedad ajena a la religión -pues entonces ella misma se consideraría a sí misma como la única religión- y la defensa de las ventajas de la presencia de la religión en la vida social, censurando por lo tanto el carácter religioso de algunos fenómenos seculares en tanto que perversión de un modelo original que sería el que sólo puede representar la religión tradicional. Un ejemplo instructivo de esta narrativa sería la crítica de la creación, por parte de la razón secular ${ }^{6}$, de sucedáneos de religión: el cientificismo, el positivismo, el biologicismo, el historicismo, etc. Aquí entrarían también las acusaciones al socialismo y al comunismo como religiones políticas ${ }^{7}$, como formas modernas de religión ${ }^{8}$. Una variante -aunque problemática- de esta

\footnotetext{
${ }^{4}$ Se trata de una acusación ya presente desde los inicios de la revolución francesa y también en la revolución rusa. Véanse, por ejemplo, los análisis de Meyer, A. J., Las Furias: violencia y terror en las revoluciones francesa y rusa, Prensas de la Universidad de Zaragoza, Zaragoza, 2014; de Duque, F., Los buenos europeos. Hacia una filosofía de la Europa contemporánea, Nobel, Oviedo, 2014, pp. 365-386: y de Rocco Lozano, V., "Revolución y republicanismo romano en Schiller y Hegel”, Philosophical Readings, 9/2, 2017, pp. 132-140.

${ }^{5}$ Aquí entraría el debate abierto en 1922 por Carl Schmitt con su Teología politica (Trotta, Madrid, 2009), al que replican, entre otros, Peterson, Blumenberg, Löwith, etc. Véase Villacañas, J. L., "La leyenda de la liquidación de la teología política", en Schmitt, C., op cit., pp. 135-180; y Rivera, A., "La secularización después de Blumenberg", Res publica, 11-12, 2003, pp. 95-142. Una perspectiva en diálogo con la historiografía se encuentra en García-Alonso, M., "Jonathan Israel et Carl Schmitt. Révolution philosophique versus contre-révolution théologique", en García-Alonso, M. (dir.), Les Lumières radicales et le politique. Études critiques sur les travaux de Jonathan Israel, Honoré Champion, Paris, 2017, pp. 355-385.

${ }^{6}$ Véase Leclerc, A., "Europa frente al desafío de las religiones: construir un espacio público más allá de la secularización", en Romerales, E., Zazo, E. (eds.), Religiones en el espacio público, Gedisa, Barcelona, 2016, pp. 53-76, donde repasa las posturas que seńalan los límites de la razón secular para atender a razones que proceden de la religión.

${ }^{7}$ Este enfoque defiende que el socialismo y el comunismo constituyen el reverso -puede que bienintencionado, pero igualmente pernicioso en sus resultados- del fascismo y el nacionalsocialismo, agrupándolos bajo el rótulo "totalitarismo". La bibliografía es inmensa a este respecto. Señalo solo algunas referencias: Vögelin, E., Las religiones politicas, Trotta, Madrid, 2014; Burleigh, M., Causas sagradas: Religión y politica en Europa. De la Primera Guerra Mundial al terrorismo islamista, Taurus, Madrid, 2006; Besançon, A., Los orígenes intelectuales del leninismo, Rialp, Madrid, 1980. Sobre la cuestión del totalitarismo, véase Enzo Traverso, Le totalitarisme. Le XXe siècle en débat, Éditions du Seuil, Paris, 2001.

${ }^{8}$ Sobre esta expresión, véase el volumen colectivo Díaz-Salazar, R., Giner, S., Velasco, F. (eds.), Formas modernas de religión, Alianza, Madrid, 2006.
} 
narrativa, que surge sobre todo desde los ańos setenta y especialmente desde la caída del Muro de Berlín y la desintegración de la URSS, saluda "el retorno de la religión”, quizá cínicamente en algunas ocasiones, como forma de protesta contra la modernidad atlántica liberal-democrática ${ }^{9} \mathrm{o}$ como otra vía de acceso a la modernidad, igualmente válida ${ }^{10}$. Lo que une a todos estos discursos y posiciones es su insatisfacción ante la razón secular, a la que le achacan su ceguera hacia la religión o su ausencia de conciencia de su propio carácter religioso. La religión, para esta narrativa, sigue estando aún muy presente, siendo parcialmente inerradicable, y la secularización completa jamás será alcanzable.

\section{Por una narrativa plural de la secularización}

Sin embargo, podemos encontrar una tercera narrativa, que denominaré "pluralista", si nos acercamos a las ciencias sociales. Se trata de una narrativa que pluraliza los sentidos de la secularización, mostrando que ésta no es el destino del proceso histórico y que la religión no es algo que desaparezca sin más o que perviva sin más, sino que se dice de forma diversa en espacios y tiempos diversos. Varios autores han matizado enormemente la tesis de la secularización, desgranando sus diferentes sentidos y corroborando su validez o su invalidez en función de numerosas circunstancias. Por un lado, José V. Casanova indica que se puede entender la secularización (1) como proceso de diferenciación de esferas o campos sociales que se emancipan del control de las instituciones y organizaciones religiosas, (2) como proceso de declive de las creencias y las prácticas religiosas o (3) como proceso de privatización de la religión y su desaparición en el espacio público ${ }^{11}$. De este modo, por ejemplo, España y EEUU serían "seculares" en general, pero en diferentes sentidos: serían similarmente seculares en su sentido 1, pero España sería más secular en su sentido 2 y más aún en su sentido 3. Pero sería menos secular que Francia en los tres sentidos. En todo caso, podríamos descender aún más en el análisis comparativo y señalar regiones españolas más seculares que otras regiones francesas o incluso regiones estadounidenses más seculares que algunas regiones españolas. Por

\footnotetext{
${ }^{9}$ Esto es lo que parece ser que Foucault vio en la revolución iraní de 1979 (veáse Roy, O., "L'énigme du soulèvement. Foucault et l'Iran", Vacarme 29, 2004, pp. 34-38).

${ }^{10}$ Dos libros escritos a principios de los años 90 del siglo XX resultan paradigmáticos: Kepel, G., La revancha de Dios: cristianos, judios y musulmanes a la reconquista del mundo, Alianza, Madrid, 2005; y Casanova, J. V., Religiones públicas en el mundo moderno, PPC, Madrid, 2000.

${ }^{11}$ Casanova, J. V., Genealogías de la secularización, Anthropos, Barcelona, 2012, pág. 19 y sigs.
} 
otro lado, Ch. Taylor también distingue tres sentidos: los dos primeros coinciden con los dos primeros de Casanova, mientras que su tercer sentido de secularización se refiere al hecho de que la creencia en Dios, a diferencia de otras épocas en las que era algo incuestionable, ahora sea una posibilidad más ${ }^{12}$. Con la introducción de estas subtesis se puede matizar con mayor precisión en qué aspectos y en qué grados una sociedad es o no es secular ${ }^{13}$. Otros sociólogos de la religión también han realizado esta labor de pluralización del concepto de secularización atendiendo a la influencia de la historia política (David Martin), de la identidad cultural (Danièle Hervieu-Léger), de las transformaciones socioeconómicas, educativas y familiares (Grace Davie) o de las dinámicas geopolíticas (Olivier Roy) ${ }^{14}$. Como se ve, en esta narrativa la secularización no es concebida en términos absolutos, sino como un conjunto de procesos interconectados. Por último, varios teóricos políticos-como Habermas- se vieron obligados a tomar en consideración este enfoque pluralista, precisamente porque la narrativa teleológica, de la que procedían por formación muchos de ellos, resultaba ya insostenible a principios del siglo XXI ${ }^{15}$. La religión, para esta tercera narrativa, se comprende de una forma más plural, en conexión con numerosos factores políticos, sociales, históricos, etc., y la secularización pierde su carácter teleológico.

La narrativa "teleológica" apunta a la supresión del elemento religioso como etapa final del proceso de secularización, mientras que la narrativa "defensiva" niega que sea posible suprimirlo por completo. A pesar de que la valoración del proceso sea diversa en ambas narrativas, coinciden sin embargo en el reconocimiento de que la "secularización" es un proceso real y de que la religión ha perdido una cierta preeminencia que anteriormente tenía. Se pueden apuntar diversos factores decisivos en este proceso: la revolución científica desde el siglo XVII y, sobre todo, la teoría de la evolución de Darwin (la ciencia); la desacralización de los textos sagrados mediante la crítica filológica (la filología); el surgimiento del método histórico-crítico y la consiguiente historización de las religiones (la historia); la búsqueda de un fundamento no religioso para la obediencia política en la época de las guerras de religión (la teoría

\footnotetext{
12 Taylor, Ch., La era secular. Tomo I, Gedisa, Barcelona, 2014, pp. 19-23.

${ }^{13}$ Zazo, E., "De cómo hemos llegado a la situación de parcialidad religiosa en (casi) todos los países europeos: Europa ante las instituciones religiosas", en Romerales, E., Zazo, E. (eds.), Religiones en el espacio público, Gedisa Barcelona, 2016, pp. 105-133.

${ }^{14}$ Martin, D., A General Theory of Secularization, Basil Blackwell, Oxford, 1978; Hervieu-Léger, D., La religión, hilo de memoria, Herder, Barcelona, 2005; Davie, G., Religion in Modern Europe: A Memory Mutates, Oxford University Press, Oxford, 2000; Roy, O., La santa ignorancia. El tiempo de la religión sin cultura, Península, Barcelona, 2010.

${ }^{15}$ Jürgen Habermas ha publicado numerosos textos sobre este asunto. Una referencia central es Entre naturalismo y religión, Paidós, Barcelona, 2006.
} 
política); la industrialización y el subsiguiente desarrollo económico y urbano (la economía); la Ilustración y sobre todo, la revolución francesa y sus consecuencias, que introdujeron una organización racional mediante códigos civiles y constituciones (el derecho); la masiva alfabetización de las masas a partir de la segunda mitad del siglo XIX (la educación); etc. Ahora bien, con independencia de las posibles consideraciones sobre cuál de estas instituciones, o qué combinación de las mismas, hayan sido decisivas, solamente la narrativa "plural" se hace cargo de la complejidad del proceso histórico. La narrativa "teleológica" y la narrativa "defensiva" no tienen en cuenta que la "secularización" no es un proceso único y completo, sino problemático, plural y lleno de matices. Algo similar ocurre con la religión.

\section{4. "Religión" es un invento reciente}

TANTO la narrativa "Teleológica" como la narrativa "defensiva" asumen una posición en el debate sobre la secularización que presupone sin embargo una concepción de la religión sobre la que, desde el punto de vista de la historia de las religiones, que es la que se ocupa de este "objeto", parece muy difícil alcanzar un acuerdo o una definición mínima. La mayoría de definiciones de "religión" suele tener en cuenta varios de los siguientes componentes: creencias en seres sobrenaturales, actos rituales, cultos, códigos morales, una comunidad de referencia, la distinción entre lo sagrado y lo profano, una cosmología, una cosmogonía, una explicación sobre el origen del ser humano, etc. Pero hasta la fecha ha resultado imposible agrupar a todas las religiones bajo una sola definición. Aunque numerosos estudiosos no han escatimado esfuerzos en la búsqueda de esa fórmula mágica -en este caso, una fórmula conceptual- que permitiría por fin fundar una "ciencia" de las religiones, parece difícil saber lo que es una religión.

Entre las propuestas más ambiciosas de la historia de las religiones destacan aquellas que consideran la la religión una realidad natural del ser humano, presente a lo largo de toda su historia y en todas las culturas. Esta comprensión se encuentra en los fundadores de la historia de las religiones del siglo XIX, como Max Müller, pero también ha sido la perspectiva de Mircea Eliade, que se ha hecho hegemónica en esta disciplina a partir de mediados del siglo XX. Esta historia de las religiones asume que lo religioso o la religiosidad es una experiencia común a todos los seres humanos, independiente de la historia, refractaria a la política y que se refiere a algo universal o eterno. Es así como se puede considerar que todas las civilizaciones o culturas tienen una "religión" o directamente "su" religión. Como se ve, este enfoque concede a la "religión" una gran autonomía al concebirla como una esfera 
irreductible y separable del resto de aspectos de la vida humana y, por lo tanto, despliega una historia de las religiones que puede dejar de lado factores como el lenguaje, los grupos sociales, la economía, los acontecimientos políticos, etc.

Pero considerar la "religión" como una esfera separada del resto de esferas sociales implica cometer un grave anacronismo. No en todas las sociedades o culturas resulta fácil encontrar una esfera claramente delimitable como religiosa. Solamente desde la comprensión de la "religión" como una realidad universal y experiencial, referida a cuestiones últimas de la existencia humana y susceptible de ser abordada de forma deshistorizada y al margen de la política, la economía, la sociedad, el género, etc., pueden "encontrarse" religiones en sociedades o culturas de todo el mundo. Esta comprensión de la "religión", por lo tanto, proyecta una categoría, la categoría de religión, en sociedades y culturas donde no existía como tal. Por anunciar nuestra tesis de una forma directa: "religión" es una categoría moderna ${ }^{16}$, tremendamente espinosa, surgida en un marco específico (en la Europa de los siglos $\mathrm{XV}$-XIX) ${ }^{17}$ y difícil de aplicar a ámbitos históricos y culturales previos a la Europa de esos siglos o ajenos a la misma, al menos hasta su "contacto" con Europa a través de la colonización:

"Religión tiene ciertamente una historia; no es una categoría originaria de las culturas antiguas. La idea de la religión como una esfera de la vida separada de la política, la economía y la ciencia es un desarrollo reciente en la historia europea que se ha proyectado hacia fuera en el espacio y hacia atrás en el tiempo, con el resultado de que la religión nos parece ahora una parte natural y necesaria de nuestro mundo." ${ }^{18}$

Es ésta una tesis polémica ${ }^{19}$; veamos varios ejemplos.

\footnotetext{
${ }^{16}$ Asad, T., Genealogies of Religion. Discipline and Reasons of Power in Christianity and Islam, Johns Hopkins University Press, Baltimore, 1993, pp. 28-29: "Yet this separation of religion from power is a modern Western norm, the product of a unique post-Reformation history [...]. My argument is that there cannot be a universal definition or religion, not only because its constituent elements and relationships are historically specific, but because that definition is itself the historical product of discursive processes."

${ }^{17}$ Véase. McCutcheon, R. T., Manufacturing Religion. The Discourse on Sui Generis Religion and the Politics of Nostalgia, Oxford University Press, Oxford, 1997; Arnal, W., McCutcheon, R. T., The Sacred is the Profane: The Political Nature of "Religion", Oxford University Press, Oxford, 2013.

${ }^{18}$ Nongbri, B., Before Religion. A History of a Modern Concept, Yale University Press, New Haven, 2013, p. 7: "[r] eligion does indeed have a history: it is not a native category to ancient cultures. The idea of religion as a sphere of life separate from politics, economics, and science is a recent development in European history, one that has been projected outward in space and backwards in time with the result that religion appears now to be a natural and necessary part of our world."

${ }^{19}$ Smith, J. Z., "Religion, Religions, Religious", en Smith, J. Z., Relating Religion: Essays in The Study of Religion, Chicago University Press, Chicago, 2004, pp. 281-282: "Religion' is not a native term; it is a term created by scholars for their intelectual purposes and therefore is theirs to define. It is a second-order, generic concept that plays the same role in establishing disciplinary horizon that a concept such as 'language' play in linguistics or "culture' plays in anthropology. There can be no disciplined study of religion without such horizon."
} 


\section{Las religiones antiguas y las religiones orientales}

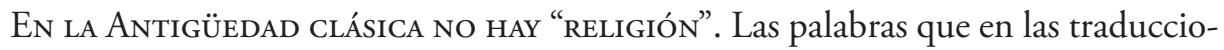
nes suelen verterse por "religión" (el griego "threskeia" y el latín "religio") se refieren a la escrupulosidad en la ejecución de los rituales dedicados a los dioses ${ }^{20}$, algo a lo que nosotros no llamaríamos "religión". En todo caso, no hacen referencia a una esfera social autónoma e independiente, sino a algo imbuido o embutido en otras esferas. En general esto es lo que ocurre en las lenguas indoeuropeas:

"No hay -y es una constatación inmediata- término indoeuropeo común para 'religión'. Aún en fecha histórica, varias de las lenguas indoeuropeas carecen de ella, cosa que no debe sorprender; la naturaleza misma de esta notación no se presta a una apelación única y constante. Si es cierto que la religión es una institución, esa institución, sin embargo, no está nítidamente separada de otras, ni planteada fuera de ellas." ${ }^{21}$

Del mismo modo ocurre con el árabe "din", que se refiere a obligaciones, costumbres, leyes, etc., y no a "religión", como suele traducirse desde hace uno o dos siglos. Cuando en textos de la Antigüedad o en textos árabes de época medieval nos encontramos con el término "religión", es muy probable que sus apariciones tengan que ver más bien con la proyección de nuestros prejuicios en esos textos mediante la traducción que con el hecho de que se comprendieran a sí mismos como "religiosos" en el sentido en que nosotros lo entendemos ${ }^{22}$. Por otra parte, la mayoría de "religiones" orientales fueron "inventadas", al menos en cuanto a su nombre, por los colonizadores e investigadores europeos: "hinduismo" data de finales del siglo XVIII; "budismo", de principios del siglo XIX; "sintoísmo", de finales del siglo $\mathrm{XIX}^{23}$. Además, numerosos estudios antropológicos han mostrado que también en

\footnotetext{
${ }^{20}$ Véase la entrada dedicada por Émile Benveniste al término "religión” en su Vocabulario de las instituciones indoeuropeas II: Poder, derecho, religión, Taurus, Madrid, 1983, pp. 397-406, donde se descarta la falsa etimología de religio como procedente de "religare", religar.

${ }^{21}$ Benveniste, E., op. cit., p. 397.

${ }^{22}$ Nongbri, B., Before Religion. A History of a Modern Concept, op. cit., pp. 35-45. Algo similar ocurre con textos de civilizaciones antiguas, previas a Grecia y Roma, cuyo "panteón” es necesariamente politeísta o henoteísta, aunque "politeísmo" y "monoteísmo" sean igualmente conceptos modernos. Véase: Assmann, J., La distinción mosaica. O el precio del monoteísmo, Akal, Tres Cantos, 2006, p. 39: "Monoteísmo y politeísmo son conceptos que proceden de debates de controversia teológica de los siglos XVII y XVIII y que son completamente inadecuados para la descripción de las religiones antiguas. [No] hubo jamás religiones que se definieran por el concepto de multiplicidad, es decir, que en lugar del lema heis theos (un dios único) hubieran elegido como lema la fórmula polloi theoi (muchos dioses) [...] La unidad de dios no es sólo la invención del monoteísmo, sino también el tema central de las religiones politeístas."

${ }^{23}$ Véase King, R., “Orientalism and the Modern Myth of 'Hinduism”, Numen 46, 2, 1999, pp. 146-185; Almond, C., The British Discovery of Buddhism, Cambridge University Press, Cambridge, 1988; Thal, S., "A Religion That Was Not a Religion: The Creation of Modern Shinto in Nineteenth-Century Japan”, en Petersen, D.
} 
la mayoría de lenguajes no indoeuropeos resulta muy difícil encontrar un término que corresponda a "religión", al menos no antes de su contacto con los colonizadores europeos ${ }^{24}$. Y, por último, incluso en la historia de las religiones más canónica se reconoce -aunque no se sigan las consecuencias hasta el final- el particular estatuto del término que da nombre a la disciplina. En la introducción a la famosa colección sobre historia de las religiones dirigida por Henri-Charles Puech, afirma Angelo Brelich:

"El concepto de religión se ha formado (y puede decirse que todavía continúa formándose) a lo largo de la historia de la civilización occidental. Es importante recordar que ninguna lengua primitiva, ninguna civilización superior arcaica, ni siquiera la griega o la romana, más próximas a nosotros, poseen un término que corresponda a este concepto que históricamente se ha definido en una época y en un medio particulares." ${ }^{25}$

Los conceptos tienen su historia; también el concepto de "religión". "Religión" -pero también "secularización"- es un concepto originario de la modernidad europea ${ }^{26}$, relativamente reciente y ligado en su origen al cristianismo y a la época imperialista europea. No hace falta decir que es insensatamente aventurado defender que estos sean sus límites, pues estos términos pueden utilizarse de forma retrospectiva -de hecho, esto es para lo que tenemos conceptos-. Pero no está de más señalar cuál es su origen, porque permite establecer diferencias y una comprensión más respetuosa con la autocomprensión de las sociedades estudiadas: si entonces seguimos empleando el término "religión" -y, por ejemplo, tratamos la "religión" griega-, entonces ha de quedar claro que nos referimos a un conjunto de prácticas insertas en contextos históricos y políticos y no a una esfera separada y autónoma de la vida social.

\section{Las religiones del mundo}

No sóLO El CONCEPTO DE "RELIGióN" sino también la clasificación de la humanidad en religiones mundiales tiene su origen en este largo proceso que tuvo lugar

R., Walhof, D. R. (eds.), The Invention of Religion: Rethinking Belief in Politics and History, Rutgers University Press, New Brunswick, 2002, pp. 100-114.

${ }^{24}$ Goody, J., La lógica de la escritura y la organización de la sociedad, Alianza, Madrid, 1990, p. 24: "En los lenguajes africanos no encuentro equivalente para la palabra occidental 'religión' (ni siquiera para 'ritual').”

${ }^{25}$ Brelich, A., "Introducción", Puech, H.-C., Historia de las religiones. 1. Las religiones antiguas. Volumen 1, Siglo XXI, 2002, pp. 34-35.

${ }^{26}$ Kippenberg, H. G., Discovering Religious History in the Modern Age, Princeton University Press, Princeton, 2002. 
entre los siglos XV y XIX ${ }^{27}$. En estos siglos, Europa “inventa” religiones en el Viejo y en el Nuevo mundo: las poblaciones colonizadas empiezan a tener "religiones" -proliferan religiones en América, Asia, África y Oceanía-, pero también se proyecta esa idea sobre las antiguas civilizaciones pretéritas (Mesopotamia, Egipto, etc.) y se "descubre" que también los griegos y los romanos tenían "religiones" 28 . Desde entonces toda sociedad o cultura tiene su propia religión, aunque se tengan que utilizar criterios variados -y que resultan extravagantes en algunos casos-, como por ejemplo el propio nombre de los pueblos (la religión griega, romana, fenicia, germana, eslava, azteca o zapoteca), las regiones geográficas y las civilizaciones (Mesopotamia, Asiria, Acadia, Caldea, Sumeria, valle del Indo, India, Mediterráneo, Mesoamérica o Sudamérica), la base económica (religiones de las sociedades de cazadores-recolectores y religiones de las sociedades agrícolas), la presencia de escrituras (las religiones del Libro y las religiones del culto y del ritual), la lengua (religiones indoeuropeas, afroasiáticas, altaicas o sino-tibetanas), el proselitismo (religiones gentilicias, cívicas, étnicas, nacionales o particularistas y religiones universalistas) o el número de dioses (politeísmo y monoteísmo), entre muchos otros. En todo caso, lo que nos interesa destacar es que los rasgos suelen estar vinculados con la historia y la política, la lengua, el territorio, la organización social, etc., esto es, con cuestiones que están más allá de la "religión".

Esta expansión inédita de religiones en los nuevos lugares conquistados y en las sociedades pasadas de las que había conocimiento viene asociada, sin embargo, al uso más antiguo de "religión", aquel que transmiten el griego "threskeia" o el latín "religio", es decir, como conjunto de cultos, usos, costumbres, obligaciones rituales, leyes, conocimientos, creencias, ceremonias, tradiciones, en suma, prácticas sociales. Hoy en día consideraríamos que estas acciones no son de por sí religiosas, ni tampoco seculares, sino una mezcla de ambas. Sin embargo, esto es lo que indican las lenguas antiguas: la religión está inserta en una serie de prácticas que desde nuestra perspectiva actual consideramos a la vez políticas, económicas, diplomáticas, ceremoniales, estéticas, etc. $\mathrm{O}$, dicho de otro modo, nosotros vemos ahí la "religión" como una esfera aún no diferenciada, pero por diferenciar. Pero así no es como se entendían ellos, lo cual quiere decir que "religión" no es término descriptivo sino reconstructivo.

De forma complementaria, durante estos siglos (del XV al XIX) la religión en Europa sufre un proceso de intelectualización. Como dice Jonathan Z. Smith, en-

\footnotetext{
${ }^{27}$ Véase el detallado estudio de Masuzawa, T., The Invention of World Religions: Or, How European Universalism Was Preserved in the Language of Pluralism, University of Chicago Press, Chicago, 2005.

${ }^{28}$ Nongbri, B., Before Religion. A History of a Modern Concept, op. cit, pp. 133-143.
} 
tre el Renacimiento y la Ilustración lo religioso dejó de comprenderse como algo ritual y práctico y pasó a comprenderse como algo más bien asociado a la creencia y a la $\mathrm{fe}^{29}$; no como una serie de hechos sociales y prácticos sino como una serie de experiencias interiores vinculadas a la creencia. Más tarde, todas las religiones serán consideradas como un conjunto de creencias sobre la realidad última observable en todas las culturas en todo tiempo histórico. Mediante el contacto a través de la colonización, en muchas lenguas se "encontró" un término que no por casualidad solía designar algunos de los aspectos anteriormente mencionados (cultos, usos, costumbres, obligaciones rituales, leyes, conocimientos, creencias, ceremonias, tradiciones) y que se hizo ampliar para que incluyera lo que desde Europa se entendía por religión y que enfatiza no tanto el aspecto cúltico-práctico sino la dimensión de la creencia.

\section{Lo"secular"}

Si SEGUimos HASTA EL FINAL EL HILO de esta argumentación, entonces resulta evidente que no sólo "religión", sino también "secular" es un término problemático. No se trata de que lo "secular" sea lo ajeno o lo extrańo de lo religioso, sino de que solamente surge como tal, de forma clara, con la "religión". O, dicho de otro modo: "secular" es un término dependiente de "religión". Desde este punto de vista, no resulta azaroso, por lo tanto, que el término "secular" sea originariamente un término "religioso": se trata de un término técnico del derecho canónico cristiano para designar el tránsito al estado secular, a una vida "laica", por parte de una persona religiosa regular, esto es, una persona que vivía hasta entonces de acuerdo a las normas de vida monásticas. Su primera constatación es de los últimos decenios del siglo XVI ${ }^{30}$, en el período en el que, de acuerdo con nuestra argumentación, consideramos que se forma la "religión" y, por lo tanto, también "lo secular". Como

\footnotetext{
${ }^{29}$ Smith, J. Z., "Religion, Religions, Religious", Op. cit., p. 271. Según este autor, este cambio puede estudiarse mediante la preferencia en el alemán de esta época por el término "Glaube" sobre el término "Religion", pues el primero enfatiza el aspecto "interno" de la creencia religiosa mientras que el segundo sigue muy ligado al aspecto "externo" y social de la religión. En este punto podemos preguntarnos: ¿es la religión un conjunto de creencias -verdaderas, falsas o indemostrables- o un marcador de pertenencia a una posible comunidad, del mismo modo que la lengua, la etnia, las costumbres compartidas, etc.? Parece que el primer sentido es propio del término religión en su sentido moderno, mientras que el primero lo es para las "proyecciones" de lo religioso en épocas pasadas.

${ }^{30}$ Marramao, G., Cielo y tierra. Genealogía de la secularización, Paidós, Barcelona, 1998, p. 19. El término más tarde se aplicó al ámbito del derecho político con el significado de expropiación de bienes eclesiásticos por parte de autoridades políticas y posteriormente, en el siglo XIX, al ámbito de la filosofía de la historia para interpretar períodos históricos, en un sentido similar a como lo emplean las narrativas de la secularización que hemos denominado "teleológica" y "defensiva".
} 
resultado, de esta comprensión de la "modernidad" de la religión se deduce que la separación entre lo religioso y lo secular es una invención reciente ${ }^{31}$, esto es, que "lo secular" es propiamente "moderno".

En su origen, "secular" es un término de procedencia cristiana, de la Europa del siglo XVI. Pero su empleo "hacia atrás", a sociedades o culturas anteriores a la Europa del siglo XVI, es siempre metafórico y debería hacerse constar. Si no es así, se corre el riesgo de proyectar distinciones modernas en la Antigüedad -o en el pasado en general-, como cuando se sostiene, por ejemplo, que la contraposición entre religioso y secular está ya presente en los primeros siglos de nuestra era con la famosa afirmación del Evangelio de Mateo 22, 21: "Pues lo del César devolvédselo al César, y lo de Dios a Dios". Difícilmente puede hallarse en esa formulación la autonomía de una esfera religiosa, opuesta casi en términos de igualdad a la esfera política. Que muchos intérpretes cristianos posteriores se hayan apoyado en este pasaje para sustentar la doctrina de las dos espadas y la separación entre Iglesia y Estado no significa que podamos encontrar divisiones modernas como la división entre lo religioso y lo secular en textos de la Antigüedad.

Si la distinción entre "religioso" y "secular" es una distinción moderna, ¿esto implica que no podemos entonces hablar ni de "religión" ni de "lo secular" en sociedades o culturas anteriores a la Europa del siglo XV? Por ejemplo, si afirmamos que la República Romana era secular o que el Imperio Romano de Oriente era religioso, ¿entonces estamos cometiendo anacronismos graves? Efectivamente, ya que imponemos un lenguaje extraño, de segundo orden. No obstante, esta falta no es algo negativo de por sí: el anacronismo no es el problema, sino la falta de conciencia de que lo es. Más bien al contrario, la labor de las ciencias humanas consiste precisamente en utilizar anacronismos -esto es, un lenguaje de segundo orden- para comprender el asunto, objeto o período estudiado. Sin embargo, ese lenguaje debe ser respetuoso con la auto-comprensión de lo estudiado y ser plenamente consciente de esa diferencia. El problema principal que queremos poner de relieve es que cuando se emplean estos términos (secular, laico, religioso, etc.) en muchas ocasiones no se es consciente de esta diferencia y se considera que la religión -o la secularidad que presupone la religión-, es una constante humana a lo largo de la historia que está presente en toda cultura. Por eso es preciso tener especial cuidado al aplicar estos términos a otras culturas o épocas previas, pues mediante este procedimiento normalmente sólo se logran proyectar los propios pre-juicios sobre lo investigado. Dicho de otro modo: no se prohíbe em-

${ }^{31}$ Véase Asad, T., Formations of the Secular. Christianity, Islam, Modernity, Stanford University Press, Stanford, 2003. 
plear el término "religión", sino que se pretende fomentar la conciencia de que "religión" es una herramienta analítica para estudiar la vida social. ${ }^{32}$

\section{8. ¿Qué hacer? Religión y secularización, conceptos peligrosos pero útiles}

¿QUÉ HACER ENTONCES? ¿Los debates sobre la religión y la secularización quedan disueltos porque (casi) todas las posturas reifican o esencializan el concepto de religión? No. Pero quedan iluminados de una nueva forma. Con estas breves notas sobre los conceptos de "religión" y "secularización" queda puesto de relieve que el relato de la modernidad como época que abandona el pasado religioso en nombre de una época secular y/o laica es insostenible. En primer lugar, porque esta construcción supone el carácter netamente religioso del pasado, cosa que no ocurre. Pensar el medievo como una época dominada por completo por la religión, una época de la que la modernidad "secular" se distanciaría, es tremendamente erróneo, un prejuicio extremadamente duradero en nuestra historiografía. Es el propio relato de la modernidad el que genera la imagen -falsa, pero productiva- de un pasado religioso del que se emancipa el presente. Pero, en segundo lugar, porque aislar lo religioso -o considerarlo como algo aislado- dificulta la comprensión de procesos sociales en los que intervienen las instituciones y las comunidades religiosas. Por eso resulta más fecunda una consideración sociológica e histórica de la religión, atenta a las transformaciones políticas, económicas, etc. En este punto resultan pertinentes las perspectivas macrohistóricas que no reducen la religión a otras esferas sociales, pero que siempre la piensan en conexión con ellas ${ }^{33}$. En este sentido podemos concluir con una crítica más detallada de las dos narrativas sobre la secularización:

a) La narrativa "teleológica" supone que la religión es superable; sin embargo, se equivoca, no porque la religión sea algo eterno en el ser humano, y por consiguiente inerradicable, sino porque la religión y lo secular van de la mano y la religión se transforma a lo largo del propio proceso de secularización. Como dice Olivier Roy:

\footnotetext{
${ }^{32}$ El análisis de "religión" como concepto histórico que señala su origen y sus límites también se puede hacer con otros términos utilizados también en este mismo texto. Por ejemplo, con los conceptos de "sociedad" o de "cultura", que también son inventos recientes. Véase Nongbri, B., Before Religion. A History of a Modern Concept, op. cit, pp. 154-159.

${ }^{33}$ Perspectivas como la sociología de la religión de Max Weber. Véase Weber, M., Sociología de la religión, Akal, Tres Cantos, 2012.
} 
"En este debate hay un gran malentendido: la secularización no ha eliminado lo religioso. Al contrario, al separar lo religioso de nuestro entorno cultural, lo hace aparecer como lo religioso puro. De hecho, la secularización ha funcionado: estamos asistiendo precisamente a la reformulación militante de la religión en un espacio secularizado que ha proporcionado autonomía a lo religioso y ha establecido con ello las condiciones de su expansión." ${ }^{34}$

Uno de los grandes hitos del proceso europeo de secularización es la consecución de la subordinación de las Iglesias al Estado. Y, por paradójico que pueda parecer a primera vista -aunque quizás no lo sea si tenemos en cuenta las consideraciones anteriores-, esta subordinación depende a su vez de la propia religión: en los países históricamente protestantes se consiguió con el paso a las doctrinas protestantes, que en general -salvo algunas excepciones como la teocrática Ginebra de Calvino-aceptaron consolidarse como Iglesias de Estado, esto es, subordinadas al Estado; en los países históricamente católicos, en cambio, se consiguió sólo con las leyes de separación de las Iglesias y el Estado, esto es, con leyes sobre la laicidad del Estado ${ }^{35}$. Como resultado de la separación entre lo religioso y lo secular, las instituciones religiosas se transforman y se adaptan al nuevo medio, funcionando de otra manera. Resulta así difícil que, aunque parezca que decaiga cada vez más, la religión se marche por el sumidero de la historia. Si tenemos en cuenta aspectos entremezclados como los que tiene en cuenta la narrativa "pluralista" (como por ejemplo la confianza en las instituciones religiosas, la asistencia a eventos religiosos, los sentimientos de religiosidad, la presencia de los intereses y/o de la agenda de las religiones en los debates políticos, la asunción del carácter cultural de una confesión particular en un territorio o nación, la financiación de las entidades religiosas y su presencia en establecimientos públicos o el conocimiento de las propias creencias religiosas), entonces resulta evidente, por un lado, que la secularización es diferente según el aspecto que consideremos y, por otro lado, que las transformaciones de las instituciones religiosas van de la mano del proceso de secularización, que no termina con ellas, sino que las modifica.

b) La narrativa "defensiva" supone que la religión es insuperable; sin embargo, se equivoca, no porque la religión sea algo eterno en el ser humano, y por

\footnotetext{
${ }^{34}$ Roy, O., La santa ignorancia. El tiempo de la religión sin cultura, op. cit., p. 18.

${ }^{35}$ Un estudio pormenorizado sobre los umbrales ("seuils") de la laicidad en Francia se encuentra en Baubérot, J., Historie de la laïcité en France, PUF, Paris, 2013. Un modelo de pluralización en el estudio de la laicidad se encuentra en su Les 7 laïcités françaises. Le modèle français de lä̈cité n'existe pas, Éditions de la Maison des sciences de l'homme, 2015.
} 
consiguiente inerradicable, sino porque la religión es una realidad en constante evolución, siempre referida a otras esferas de la vida social. Como dice Olivier Roy:

“El secularismo produce religión. No hay un 'retorno' de lo religioso, hay una mutación. Y sin duda esa mutación es pasajera; no conduce necesariamente a una nueva era religiosa." 36

Aunque resulte chocante, quien define hoy lo que es una religión -al menos en términos jurídicos y políticos-, no son las propias organizaciones religiosas, sino el Estado. ¿QQuién si no decide si una niña puede acceder a la escuela pública con velo, o si una persona de religión judía puede hacer el examen de oposición, si éste cae en sábado, otro día? En definitiva: ¿qué diferencia hoy a una religión de una secta? El reconocimiento del Estado como tal. Como bien se ve en el caso español, es el Estado -el Ministerio de Justicia, en concreto-, quien clasifica y ordena las diferentes religiones ${ }^{37}$ : religiones cuya relación con el Estado está mediada por un Concordato (Iglesia católica); religiones con las que el Estado suscribe acuerdos de cooperación (Iglesias evangélicas, comunidades judías, comunidades musulmanas); y religiones a las que reconoce "notorio arraigo" (Iglesia de Jesucristo de los Santos de los últimos días, Testigos de Jehová, Budismo, Iglesia ortodoxa). A su vez, esta ordenación produce una uniformización en términos organizativos en las diferentes comunidades religiosas. Aunque el Estado no intervenga en asuntos de organización interna (por ejemplo, ¿̨podría exigir cuotas de género, como en las empresas?), quiere tener un interlocutor identificable y esa exigencia tiene efectos reales sobre las entidades religiosas. Pero en todo caso, a duras penas sería posible imaginar una nueva era de expansión religiosa ${ }^{38}$.

Como hemos defendido a lo largo del texto, la narrativa "pluralista" concede que "religión" y "secularización" se dicen de muchas maneras y amplía las formas de

\footnotetext{
${ }^{36}$ Roy, O., La santa ignorancia. El tiempo de la religión sin cultura, op. cit., p. 19.

${ }^{37}$ Una ordenación que tiene importantísimas repercusiones sobre la enseñanza de las religiones en la escuela pública. Véase Díez de Velasco, F., "La enseñanza de las religiones (en plural) en la escuela en España, Historia, problemas y perspectivas", Studi e Materiali di Storia delle Religioni, 75/2 ,2009, pp. 497-534.

${ }^{38} \mathrm{Y}$ aunque así ocurriera, los fundamentalismos religiosos "triunfantes" son igualmente grandes productores de secularidad. Como ha estudiado Olivier Roy, los movimientos fundamentalistas que, en varios países de mayoría musulmana, han intentado crear una teocracia, acaban generando involuntariamente una mayor secularización en otros aspectos. Véase Roy, O., L'échec de l'islam politique, Éditions du Seuil, 2015, pp. 43-47.
} 
considerar lo religioso desde un punto de vista cercano a las ciencias sociales que, además, se hace cargo de factores políticos, económicos, sociales, de género, etc. En este sentido, resulta una gran corrección a la narrativa "teleológica" y a la narrativa "defensiva", que comprenden la secularización como un proceso completo y la religión como algo estable e identificable. Su potencia explicativa resulta innegable y los estudios realizados desde esta perspectiva han abierto nuevos ámbitos de investigación, complejificando un asunto tan escurridizo y peligroso como la religión. Desde este punto de vista, finalizamos con las dos siguientes conclusiones: que es la modernidad la que da origen a los conceptos de "religión" y "secularización" 39 y que las religiones han de ser consideradas desde una perspectiva social, política, económica, de género, etc., pues también funcionan como marcadores sociales, como transmisores de una tradición, como identificadores de pertenencia a grupos o comunidades, etc. ${ }^{40}$

\footnotetext{
${ }^{39}$ Sin embargo, las disquisiciones teóricas y los arreglos políticos en torno a la gestión de la diversidad social -y protorreligiosa- son tan antiguos como los primeros asentamientos agrícolas humanos y los grandes imperios de la Antigüedad. Un buen análisis macrohistórico sobre las grandes civilizaciones históricas se encuentra en Collins, R., Sociología de la filosofía. Una teoría global del cambio intelectual, Hacer, Barcelona, 2005.

${ }^{40}$ He tratado este asunto en Zazo, E., "Cristianismo difuso e islam minoritario en las ciudades europeas", Philosophical Readings 8/3, 2016, pp. 230-237.
} 


\section{Referencias Bibliográficas}

Almond, C., The British Discovery of Buddhism, Cambridge University Press, Cambridge, 1988.

Arnal, W., McCutcheon, R. T., The Sacred is the Profane: The Political Nature of "Religion", Oxford University Press, Oxford, 2013.

Asad, T., Genealogies of Religion. Discipline and Reasons of Power in Christianity and Islam, Johns Hopkins University Press, Baltimore, 1993.

Asad, T., Formations of the Secular. Christianity, Islam, Modernity, Stanford University Press, Stanford, 2003.

Assmann, J., La distinción mosaica. O el precio del monoteísmo, Akal, Tres Cantos, 2006.

Baubérot, J., Historie de la laïcité en France, PUF, Paris, 2013.

Baubérot, J., Les 7 laïcités françaises. Le modèle français de laïcité n'existe pas, Éditions de la Maison des sciences de l'homme, 2015.

Benveniste, E., Vocabulario de las instituciones indoeuropeas II: Poder, derecho, religión, Taurus, Madrid, 1983.

Berger, P., Davie, G., y Fokas, E., Religious America, Secular Europe? A Theme and Variations, Ashgate, Aldershot, 2008.

Besançon, A., Los origenes intelectuales del leninismo, Rialp, Madrid, 1980.

Brelich, A., "Introducción", Puech, H.-C., Historia de las religiones. 1. Las religiones antiguas. Volumen 1, Siglo XXI, 2002.

Burleigh, M., Causas sagradas: Religión y política en Europa. De la Primera Guerra Mundial al terrorismo islamista, Taurus, Madrid, 2006.

Casanova, J. V., Religiones públicas en el mundo moderno, PPC, Madrid, 2000.

Casanova, J. V., Genealogías de la secularización, Anthropos, Barcelona, 2012.

Collins, R., Sociología de la filosofía. Una teoría global del cambio intelectual, Hacer, Barcelona, 2005.

Davie, G., Religion in Modern Europe: A Memory Mutates, Oxford University Press, Oxford, 2000.

Díaz-Salazar, R., Giner, S., Velasco, F. (eds.), Formas modernas de religión, Alianza, Madrid, 2006. 
Díez de Velasco, F., "La enseñanza de las religiones (en plural) en la escuela en España, Historia, problemas y perspectivas", Studi e Materiali di Storia delle Religioni, 75/2, 2009, pp. 497-534.

Duque, F., Los buenos europeos. Hacia una filosofía de la Europa contemporánea, Nobel, Oviedo, 2014.

García-Alonso, M., "Jonathan Israel et Carl Schmitt. Révolution philosophique versus contre-révolution théologique", en García-Alonso, M. (dir.), Les Lumières radicales et le politique. Etudes critiques sur les travaux de Jonathan Israel, Honoré Champion, Paris, 2017, pp. 355-385.

Goody, J., La lógica de la escritura y la organización de la sociedad, Alianza, Madrid, 1990.

Habermas, J., Entre naturalismo y religión, Paidós, Barcelona, 2006.

Hervieu-Léger, D., La religión, hilo de memoria, Herder, Barcelona, 2005.

Kepel, G., La revancha de Dios: cristianos, judios y musulmanes a la reconquista del mundo, Alianza, Madrid, 2005.

King, R., "Orientalism and the Modern Myth of 'Hinduism'”, Numen 46, 2, 1999, pp. 146-185.

Kippenberg, H. G., Discovering Religious History in the Modern Age, Princeton University Press, Princeton, 2002.

Leclerc, A., "Europa frente al desafío de las religiones: construir un espacio público más allá de la secularización”, en Romerales, E., Zazo, E. (eds.), Religiones en el espacio público, Gedisa, Barcelona, 2016, pp. 53-76.

Marramao, G., Cielo y tierra. Genealogía de la secularización, Paidós, Barcelona, 1998.

Martin, D., A General Theory of Secularization, Basil Blackwell, Oxford, 1978.

Masuzawa, T., The Invention of World Religions: Or, How European Universalism Was Preserved in the Language of Pluralism, University of Chicago Press, Chicago, 2005.

McCutcheon, R. T., Manufacturing Religion. The Discourse on Sui Generis Religion and the Politics of Nostalgia, Oxford University Press, Oxford, 1997.

Meyer, A. J., Las Furias: violencia y terror en las revoluciones francesa y rusa, Prensas de la Universidad de Zaragoza, Zaragoza, 2014.

Nongbri, B., Before Religion. A History of a Modern Concept, Yale University Press, New Haven, 2013. 
Rivera, A., "La secularización después de Blumenberg", Res publica, 11-12, 2003, pp. 95-142.

Rocco Lozano, V., "Revolución y republicanismo romano en Schiller y Hegel", Philosophical Readings, 9/2, 2017, pp. 132-140.

Romerales, E., "Reacciones en Europa frente al fanatismo islámico", en Romerales, E., Zazo, E. (eds), Religiones en el espacio público, Gedisa Barcelona, 2016, pp. 77-104.

Roy, O., "L'énigme du soulèvement. Foucault et l'Iran", Vacarme 29, 2004, pp. 34-38.

Roy, O., La santa ignorancia. El tiempo de la religión sin cultura, Península, Barcelona, 2010.

Roy, O., La laïcité face à l'islam, Pluriel, Paris, 2013.

Roy, O., L'échec de l'islam politique, Éditions du Seuil, 2015.

Smith, J. Z., "Religion, Religions, Religious", en Smith, J. Z., Relating Religion: Essays in The Study of Religion, Chicago University Press, Chicago, 2004.

Schmitt, C., Teología politica, Trotta, Madrid, 2009.

Taylor, Ch., La era secular. Tomo I, Gedisa, Barcelona, 2014.

Thal, S., "A Religion That Was Not a Religion: The Creation of Modern Shinto in Nineteenth-Century Japan", en Petersen, D. R., Walhof, D. R. (eds.), The Invention of Religion: Rethinking Belief in Politics and History, Rutgers University Press, New Brunswick, 2002, pp. 100-114.

Traverso, E., Le totalitarisme. Le XXe siècle en débat, Éditions du Seuil, Paris, 2001.

Villacańas, J. L., "La leyenda de la liquidación de la teología política", en Schmitt, C., Teología política, Trotta, Madrid, 2009, pp. 135-180.

Vögelin, E., Las religiones politicas, Trotta, Madrid, 2014.

Weber, M., Sociología de la religión, Akal, Tres Cantos, 2012.

Zazo, E., "De cómo hemos llegado a la situación de parcialidad religiosa en (casi) todos los países europeos: Europa ante las instituciones religiosas" en Romerales, E., Zazo, E. (eds.), Religiones en el espacio público, Gedisa, Barcelona, 2016, pp. 105-133.

Zazo, E., "Cristianismo difuso e islam minoritario en las ciudades europeas", Philosophical Readings 8/3, 2016, pp. 230-237. 
